\title{
The impact of passive immunisation against BMPRIB and BMP4 on follicle development and ovulation in mice
}

\author{
S Al-Samerria, I Al-Ali ${ }^{1}$, J R McFarlane ${ }^{1}$ and G Almahbobi \\ School of Biomedical Sciences, Curtin Health Innovation Research Institute (CHIRI), Curtin University, Kent Street, \\ Bentley, Perth, Western Australia 6102, Australia and ${ }^{1}$ Centre for Bioactive Discovery in Health and Ageing, \\ University of New England, Armidale, New South Wales 2351, Australia
}

Correspondence should be addressed to G Almahbobi; Email: g.almahbobi@curtin.edu.au

\begin{abstract}
The primordial follicle reserve is the corner stone of female fertility and determines the longevity and quality of reproduction. Complete depletion of this reserve will lead to primary infertility, and the key-limiting step of follicle depletion is the transition from primordial to primary follicles. It has been reported that this process is gonadotrophin-independent, but other conflicting reports are indicated otherwise and this discrepancy needs to be unequivocally clarified. The aim of this study was to investigate the role of bone morphogenetic proteins (BMPs) in the regulation of folliculogenesis in mice passively immunised against BMP receptor 1B (BMPRIB) and $B M P 4$. While a stereological study revealed that the numbers of primordial follicles in immunised mice were significantly higher when compared with control animals, treatment with equine chorionic gonadotrophin showed no effect. In parallel, immunofluorescence microscopy revealed the presence of BMPRIB but not FSH receptor in primordial follicles. The number of primary follicles in immunised mice were also significantly increased when compared with control animals. After puberty, the rates of depletion of primordial and primary follicles were increased with age, particularly in treated animals; however, there was no significant difference between the treatment groups of the same age. Based on these results together with our previous reports in sheep and mice, we confirm that the attenuation of BMP signalling system can be an effective approach to sustain the primordial follicle reserve while promoting the development of growing follicles, ovulation and consequently overall female fertility.
\end{abstract}

Reproduction (2015) 149 403-411

\section{Introduction}

In the ovary, primordial follicles contain arrested primary oocytes, which remain viable throughout life. Among other factors, the numbers and quality of these follicles determine the longevity of female fertility. Every day a few primordial follicles begin development into primary follicles, of these only a small fraction will be destined to complete full folliculogenesis and ovulate, while all the rest die via atresia at some point along the follicular development pathway (McGee \& Hsueh 2000). This process of continuous follicular atresia with age and repetition of ovulation after puberty results eventually in complete depletion of this fertility reserve and hence the cessation of ovarian function in mammals and specifically menopause in women. Therefore, the initial transition from primordial to primary follicles, also known as initial follicle recruitment (McGee \& Hsueh 2000, Depalo et al. 2003, Thomas \& Vanderhyden 2006), is the key limiting step of folliculogenesis and thus follicle depletion.
Ovarian folliculogenesis operates mainly under the control of gonadotrophins (follicle-stimulating hormone $(\mathrm{FSH})$ and luteinizing hormone $(\mathrm{LH})$ ), whose levels are regulated by the hypothalamic-pituitary-gonadal axis (Fauser \& Van Heusden 1997). Specifically, it has been commonly believed that FSH may be involved in the initial recruitment of primordial follicles (Meredith et al. 1992, Flaws et al. 1997). However, recent observations have demonstrated that these follicles develop normally in mice lacking active FSH or FSH receptor (FSHR) due to gene mutation in FSH $\beta$ subunit (Siegel et al. 2013) or FSHR (Dierich et al. 1998), suggesting that initial follicle recruitment is gonadotrophin independent (Orisaka et al. 2009). Instead, this process appears to be regulated by several intraovarian factors (Tanwar et al. 2008), such as the bone morphogenetic proteins (BMPs) (Lee et al. 2001, Knight \& Glister 2003, Abir et al. 2008), and this discrepancy requires further investigation.

BMPs are members of the TGF- $\beta$ superfamily and signal through their serine/threonine kinase receptors (Massague 1998), which are of two types: type I 
(BMPRIA and BMPRIB) and type II (Cheifetz et al. 1987, Chang et al. 2002, Derynck \& Zhang 2003). The BMP signalling system comprises several BMP ligands, BMPR type I and II, and the intracytoplasmic transcription factors SMADs (Shimasaki et al. 2004).

$B M P 4$ mRNA is primarily expressed in theca cells, whereas BMPRIB is predominantly expressed in the granulosa cells of rat ovaries (Shimasaki et al. 1999, Erickson \& Shimasaki 2003, Tanwar \& McFarlane 2011), indicating a paracrine mode of action. BMPRIB is the main and common receptor used by several intraovarian BMPs such as BMP 2, 4, 7, and 15 (Shimasaki et al. 2004). On the other hand, the dominant intraovarian BMP4 exerts a major role in the formation of primordial germ cells (oocytes) (Shimasaki et al. 1999, 2004), recruitment of primordial to primary follicles in sheep (Ruoss et al. 2009) and rat (Nilsson \& Skinner 2003), oestradiol production, and inhibition of progesterone secretion and ovulation (Lawson et al. 1999, Shimasaki et al. 1999, Nilsson \& Skinner 2003, Ruoss et al. 2009).

In rodent models, the role of BMPs in initial follicle recruitment and overall ovarian function has been investigated, including in vitro culture of mouse follicular cells (Shimasaki et al. 2004) and cultured whole ovaries of rat (Nilsson \& Skinner 2003). We have supported these in vitro studies using in vivo models namely the Booroola sheep (Ruoss et al. 2009) and mice passively immunised against BMP4 (Tanwar et al. 2008), both models are characterised by attenuated action of the BMP signalling system, similar to that initially described in Bmp $4^{\text {lacZneo }}$ haplo-insufficient mice (Lawson et al. 1999). Our recent report has confirmed that the attenuation of the BMP signalling system by a natural point mutation of BMPRIB in Booroola sheep reduces the rate of primordial follicle recruitment, while increasing primary follicle survival (Ruoss et al. 2009). However, it has not yet been determined whether such an effect of BMPs is a sheep species and/or a Booroola strain specific phenomenon or can be applied to other species and different experimental conditions. Although we have confirmed the role of BMP4 in primordial follicle recruitment in mice after passive immunisation (Tanwar et al. 2008), this preliminary report was based only on immediate observations after a short-term treatment and using manual counting of follicles.

The aim of this study was to investigate the role of the BMP signalling system in the regulation of primordial follicle depletion in an in vivo model of mice passively immunised against BMPRIB and BMP4, using a computer-based stereological method (Braendgaard \& Gundersen 1986, Myers et al. 2004, Ruoss et al. 2009). Specifically, the study aimed to quantify the numbers of primordial and primary follicles and calculate their ratios in different treatment and age groups of mice. The role of gonadotrophins and their interaction with the BMP system in follicular development and ovulation were also examined.

\section{Materials and methods}

\section{Antibodies}

Antibodies to BMP4 (JMCK\#54) and BMPRIB (JMCK\#59) were raised in chickens against synthetic peptides (Invitrogen Australia) equivalent to amino acids 88-102 (ISMLYLDEYDKVVLK) of mouse BMP4 and amino acids 103-117 of mouse BMPRIB (NKDLHPTLPPLKDRD). The antibodies were raised and characterised in our laboratory as described previously (Tanwar \& McFarlane 2011). In brief, the synthetic peptides were conjugated to diphtheria toxoid (CSL) and emulsified in Freunds complete adjuvant (Sigma-Aldrich Pty Ltd) for the primary vaccination and in Freunds incomplete adjuvant for booster injections. The primary vaccination contained $50 \mu \mathrm{g}$ of peptide, while all boosters contained $25 \mu \mathrm{g}$ of peptide. The antibodies were purified from egg yolks using a combination ammonium sulphate and octanoic acid as described by McKinney \& Parkinson (1987). The cross reactivity of BMP2 and BMP7 was $<0.5 \%$ for the anti-BMP4 antibody and the specificity of the BMPRIB antibody was determined by competitive binding ELISA test against random peptides (Tanwar \& McFarlane 2011). The DELTA-BLAST analysis showed that the sequence was specific to mouse BMPRIB with no potential binding to other proteins. These antibodies were used to passively vaccinate mice using $50 \mu \mathrm{g}$ of purified antibody in $100 \mu \mathrm{l}$ of saline injected subcutaneously. The dose of antibody was similar to that we have used previously (Tanwar et al. 2008) and was determined by pilot studies.

\section{Animals and passive immunisation}

Female Swiss mice at 21 days of age were housed at the Physiology Animal House facility, University of New England, NSW, Australia, where all the in vivo experiments were carried out in accordance with the Australian code of practice for the care and use of animals for scientific purposes, and approved by the University of New England Animal Ethics Committee.

To investigate the effects of attenuating the BMP signalling system on follicle developmental dynamics in the presence and absence of exogenous gonadotrophins, 3-week-old female mice were divided into six groups ( $n=4$ each group) and daily s.c. injections $(100 \mu \mathrm{l})$ of the following treatments were given for 7 days: the first group, $50 \mu$ g anti-BMP4 $(n=20)$; the second group, $50 \mu \mathrm{g}$ anti-BMPRIB $(n=20)$; the third group, $1 \mathrm{IU}$ equine chorionic gonadotrophin (eCG; Bioniche Animal Health, Armidale, NSW, Australia) $(n=4)$; the fourth group, $1 \mathrm{IU}$ eCG + anti-BMP4 $(n=4)$; the fifth group, 1 IU eCG + antiBMPRIB $(n=4)$; and the sixth group, $50 \mu \mathrm{g}$ purified nonimmune chicken $\operatorname{lgY}$, as a control group $(n=20)$. Four mice of each group were killed by $\mathrm{CO}_{2}$ asphyxiation $24 \mathrm{~h}$ after the last injection. The remaining animals of first, second, and sixth groups were kept for further periods of 2, 6, 12, or 24 weeks without treatment before they were killed at 6, 10, 16, or 28 weeks of age respectively ( $n=4$ for each group). The total number of animals used per each full experiment was 72 and this experiment was repeated three times (216 mice in total). However, only 72 animals (four animals per treatment group per age), randomly selected from the three experiments, were 
used in this study. All other animals were kept for other investigations. The ovaries were collected and used for further studies as detailed below.

\section{Ovaries and histology}

The collected ovaries were dissected to remove excess surrounding tissues and one from each animal was fixed in Bouin's solution, paraffin embedded, and processed for histological study. The whole ovaries were exhaustively cut into at $5 \mu \mathrm{m}$ serial sections using a rotary microtome. The sections were consecutively labelled, mounted on a glass slide and stained with haematoxylin and eosin for further stereological studies. For this purpose, the stages of follicle development were classified according to previous reports (Myers et al. 2004, Ruoss et al. 2009). In brief, primordial follicles appeared as a primary oocyte surrounded by a single layer of squamous granulosa cells (Fig. 1, inset), whereas primary follicles showed a complete single layer of cuboidal granulosa cells (Fig. 2, inset). The same serial sections were used to count the numbers of corpora lutea in each ovary for the determination of relative ovulation rate. Five other ovaries each that represents the five different ages of control animals were used for immunofluorescence studies of receptor expression. These ovaries were snap frozen in liquid nitrogen and stored at $-80{ }^{\circ} \mathrm{C}$ before they were cryosectioned for immunofluorescence localisation of BMPRIB and FSHR.

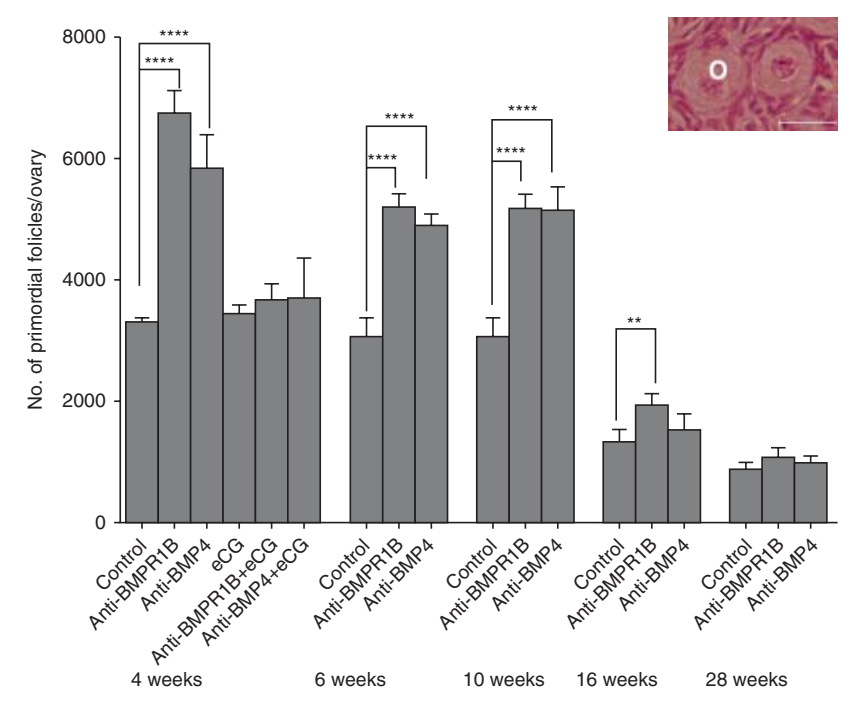

Figure 1 Stereological quantification of primordial follicles in different treatment groups. The estimated follicle number per ovary was calculated in every 10 th section ( $50 \mu \mathrm{m}$ interval) using a computerised stereological method. The mean \pm s.D. of the estimated total number of primordial follicles per ovary was significantly higher in mice passively immunised compared with controls at most ages as indicated. At week 4, eCG treatment either alone or in combination with antibodies showed no difference compared with controls. ${ }^{* *} P<0.01$; ${ }^{* * *} P<0.0001$. Inset, a group of primordial follicles showing oocytes $(\mathrm{O})$ enclosed by flattened squamous follicular cells. Bar $=50 \mu \mathrm{m}$.

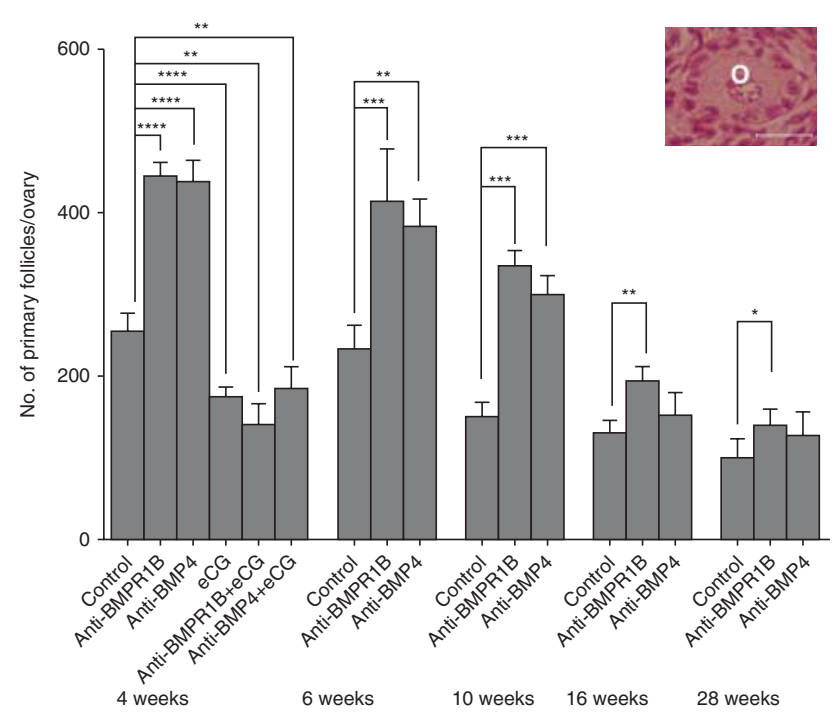

Figure 2 Stereological quantification of primary follicles in different treatment groups. The estimated follicle number per ovary was calculated in every 10 th serial section $(50 \mu \mathrm{m}$ interval) using a computerised stereological method. The mean \pm s.D. of the estimated total number of primary follicles per ovary was significantly higher in mice passively immunised with anti-BMPRIB compared with control group at all animals ages. In mice immunised with anti-BMP4, a significant difference was found up to age 10 weeks. At week 4, eCG treatment with or without antibodies revealed significant reduction in primary follicle numbers. ${ }^{*} P<0.05$; ${ }^{* *} P<0.01$; ${ }^{* * *} P<0.001$; $* * * * P<0.0001$. Inset, a primary follicle shows an oocyte $(\mathrm{O})$ surrounded by a complete layer of cuboidal granulosa cells. Bar $=50 \mu \mathrm{m}$.

\section{Stereology of ovarian follicles}

The estimated total numbers of primordial and primary follicles in the entire ovary were counted by the physical dissector method as originally described (Braendgaard \& Gundersen 1986, Gundersen et al. 1988). Every 10th section (50 $\mu \mathrm{m}$ interval) selected in the order generated by the microtome was used to provide a non-biased representation for the whole ovary. The section boundaries were determined under low magnification for the placement of the $150 \times 150 \mu \mathrm{m}$ $\left(22500 \mu \mathrm{m}^{2}\right.$ ) sampling grid, and the section sampling was performed as previously described (Myers et al. 2004) to generate 32-72 sampling frames. Follicle counting was done using $\times 40$ oil immersion objective $\left(N_{A}=1.0\right)$, fitted to an Olympus BX microscope. The microscope supported by a computerised Stereo Investigator station (Stereo Investigator software version 8, MicroBrightField, Inc., Colchester, MA, USA) was used for the data collection and analysis. The procedure of follicle counting has been fully described previously (Ruoss et al. 2009).

\section{Estimation of ovulation rates}

The estimation of ovulation rates in mice from different treatment groups was carried out by counting the numbers of (new and old) corpora lutea present in each selected ovary, obtained from treated and control animals of 4, 10, and 16 weeks of age $(n=3 \times 4=12)$. The numbers of the corpora lutea 
Table 1 Mean estimated total numbers and ratios of primordial follicles in different ages of animals.

\begin{tabular}{|c|c|c|c|c|c|c|c|c|c|c|}
\hline \multirow[b]{2}{*}{ Treatment } & \multicolumn{2}{|c|}{$\begin{array}{l}4 \text { weeks ( } n=4 \\
\text { in each group) }\end{array}$} & \multicolumn{2}{|c|}{$\begin{array}{l}6 \text { weeks ( } n=4 \\
\text { in each group) }\end{array}$} & \multicolumn{2}{|c|}{$\begin{array}{l}10 \text { weeks }(n=4 \\
\text { in each group) }\end{array}$} & \multicolumn{2}{|c|}{$\begin{array}{l}16 \text { weeks ( } n=4 \\
\text { in each group) }\end{array}$} & \multicolumn{2}{|c|}{$\begin{array}{l}28 \text { weeks ( } n=4 \\
\text { in each group) }\end{array}$} \\
\hline & Mean \pm s.D. & Ratio & Mean \pm s.D. & Ratio (\%) & Mean \pm s.D. & Ratio (\%) & Mean \pm s.D. & Ratio (\%) & Mean士s.D. & Ratio (\%) \\
\hline Control & $3290 \pm 37$ & NA & $3025 \pm 167$ & 92 & $2663 \pm 40$ & 81 & $1329 \pm 99$ & 40 & $878 \pm 57$ & 27 \\
\hline Anti-BMPR1B & $6741 \pm 185$ & NA & $5183 \pm 116$ & 77 & $5679 \pm 198$ & 84 & $1939 \pm 85$ & 29 & $1070 \pm 75$ & 16 \\
\hline Anti-BMP4 & $5831 \pm 281$ & $\mathrm{NA}$ & $4893 \pm 86$ & 84 & $4509 \pm 193$ & 77 & $1517 \pm 137$ & 26 & $989 \pm 53$ & 17 \\
\hline
\end{tabular}

The ratios of primordial follicles, expressed as a percentage of the estimated total numbers at a given age to the numbers at week 4 , gradually decreased with age. There was no significant difference in the ratio of follicle loss between the different groups of treatment at a given age. $n$, number of animals.

were counted in every 40th section of the ovaries, in the order generated by the microtome, leaving $200 \mu \mathrm{m}$ intervals that are slightly larger than the average size of individual corpus luteum in mice ovaries (Sandrock et al. 2009). This method provides a non-biased representation of the whole ovary and avoids multiple counting of the same corpus luteum.

\section{Immunofluorescence localisation of receptors}

The ovarian cryosections $(10 \mu \mathrm{m})$ were mounted on Superfrost slides (HD Scientific Supplies Pty Ltd, Australia) and used for indirect immunofluorescence labelling as described previously (Hall \& Almahbobi 1997, Al-Samerria \& Almahbobi 2014). Briefly, the tissue sections were fixed in 4\% paraformaldehyde, and polyclonal goat anti-BMPRIB (sc-5679) and anti-FSHR (sc-7798) (Santa Cruz Biotechnology) were applied at $4 \mu \mathrm{g} / \mathrm{ml}$ overnight at $4{ }^{\circ} \mathrm{C}$. For the negative control, the tissue sections were incubated with $10 \%$ (v:v) pre-immune goat serum (Life Technology) instead of primary antibodies. A polyclonal rabbit anti-goat IgG second antibody conjugated to Alexa 488 fluorochrome (A-11078, Life Technology) was applied to all slides at $4 \mu \mathrm{g} / \mathrm{ml}$ for $45 \mathrm{~min}$ at room temperature. The slides were washed and mounted in Prolonged Diamond anti-fade mounting media with DAPI (P-36962, Life Technology). The slides were examined using a Carl Zeiss semi-confocal microscope equipped with a Carl Zeiss Digital Camera 200 M Axiovert (Carl Zeiss, Sydney, NSW, Australia) and images were captured using AsioVision 4.2.8 image analyzer software (Carl Zeiss).

\section{Calculation and statistical analyses}

Statistical analysis was performed using two-way ANOVA followed by Tukey's post hoc test for multiple comparisons to compare the estimated numbers between control and treated animal groups in Prism version 6 (Graph Pad Software, La Jolla,
CA, USA) and the data were presented as \pm s.D. The differences between means were considered significant when $P<0.05$. The ratios of primordial and primary follicle numbers in different ages of animals were calculated as the percentages of follicle numbers at a given age relevant to the numbers of follicles in animals of the same treatment group at week 4 of age, as given in Tables 1 and 2 .

\section{Results}

\section{Stereological quantification of primordial and primary follicles in different ages}

Regardless of treatment, the overall mean of estimated total numbers of primordial and primary follicles per ovary significantly decreased with age, with a noticeably sharp reduction at the later age of animals. Specifically, at the 28th week of age, the follicle numbers were significantly $(P<0.0001)$ reduced in each individual treatment group when compared with those at week 4 (Tables 1, 2 and Figs 1, 2). Only 16-27 and 29-39\% of the primordial and primary follicles, respectively, were found in mice at week 28 of age compared with those at week 4 . The reduction in follicle amount showed no significant difference neither between the two immunised animal groups nor between the immunised and control animals (Tables 1 and 2).

\section{Stereological quantification of primordial follicles in different treatment groups}

The estimated total numbers of primordial follicles in animals immediately after treatment with anti-BMPRIB and anti-BMP4 antibodies at 4 weeks of age were significantly $(P<0.0001)$ higher $(205$ and $177 \%$, respectively) than that in control mice (Fig. 1). The numbers

Table 2 Mean estimated total numbers and ratios of primary follicles in different ages of animals.

\begin{tabular}{|c|c|c|c|c|c|c|c|c|c|c|}
\hline \multirow[b]{2}{*}{ Treatment } & \multicolumn{2}{|c|}{$\begin{array}{l}4 \text { weeks ( } n=4 \\
\text { in each group) }\end{array}$} & \multicolumn{2}{|c|}{$\begin{array}{l}6 \text { weeks ( } n=4 \\
\text { in each group) }\end{array}$} & \multicolumn{2}{|c|}{$\begin{array}{l}10 \text { weeks ( } n=4 \\
\text { in each group) }\end{array}$} & \multicolumn{2}{|c|}{$\begin{array}{l}16 \text { weeks ( } n=4 \\
\text { in each group) }\end{array}$} & \multicolumn{2}{|c|}{$\begin{array}{l}28 \text { weeks ( } n=4 \\
\text { in each group) }\end{array}$} \\
\hline & Mean士s.D. & Ratio & Mean \pm S.D. & Ratio (\%) & Mean \pm s.D. & Ratio (\%) & Mean \pm s.D. & Ratio (\%) & Mean \pm S.D. & Ratio $(\%)$ \\
\hline Control & $254 \pm 12$ & NA & $232 \pm 15$ & 91 & $149 \pm 9$ & 59 & $130 \pm 8$ & 51 & $100 \pm 12$ & 39 \\
\hline Anti-BMPR1B & $444 \pm 8$ & NA & $412 \pm 32$ & 93 & $334 \pm 9$ & 75 & $193 \pm 9$ & 43 & $139 \pm 10$ & 31 \\
\hline Anti-BMP4 & $438 \pm 13$ & NA & $382 \pm 17$ & 87 & $300 \pm 11$ & 68 & $151 \pm 14$ & 34 & $127 \pm 13$ & 29 \\
\hline
\end{tabular}

The ratios of primary follicles, expressed as a percentage of the estimated total numbers at a given age to the numbers at week 4 , gradually decreased with age. There was no significant difference in the ratio of follicle loss between the different groups of treatment at a given age. $n$, number of animals. 
remained significantly $(P<0.0001)$ higher at 6 and 10 weeks, but showed a sharp reduction in older animals. Although the numbers were still elevated in both treated groups beyond week 10, a significant difference $(P<0.01)$ was only observed in animals treated with anti-BMPRIB at 16 weeks of age. At 4 weeks, there was no difference in the numbers of primordial follicles between the control and those animals treated with eCG. However, treatment with eCG abolished the immunisation-induced higher numbers of primordial follicles (Fig. 1).

\section{Stereological quantification of primary follicles in different treatment groups}

Analysis of these data showed that the estimated total numbers of primary follicles in animals immediately after treatment with anti-BMPRIB and anti-BMP4 antibodies at 4 weeks were significantly $(P<0.0001)$ higher (175 and $172 \%$ respectively) than that in control mice (Fig. 2). In animals treated with anti-BMPRIB, the numbers of primary follicles remained significantly higher at $6(P<0.001), 10(P<0.001), 16(P<0.01)$ and $28(P<0.05)$ weeks. In animals treated with antiBMP4, the numbers of primary follicles remained significantly higher at $6(P<0.01)$ and $10(P<0.001)$ weeks, but no significant difference was found at 16 and 28 weeks (Fig. 2).

In contrast to the case of primordial follicles, treatment with eCG alone or as a supplement with anti-BMPRIB significantly reduced $(P<0.0001,59 \%)$ the estimated numbers of primary follicles at 4 weeks. Similar results were observed after treatment with anti-BMP4 $(P<0.01)$ (Fig. 2).

\section{Immunofluorescence localisation of BMPR1B and FSHR}

Immunofluorescence observation revealed positive staining for BMPRIB in both primordial and primary follicles, as well as in the stromal cells (Fig. 3C, G and $\mathrm{H})$. Staining of FSHR showed positive labelling only in the granulosa cells of primary follicles (Fig. 3F), but not in primordial follicles (Fig. 3B). The negative control specimen using pre-immune serum instead of primary antibodies against BMPRIB or FSHR showed no staining in either follicular or stromal cells (Fig. 3D).

\section{Ovulation rates}

A considerable increase in ovulation rate relative to age was observed in all animals irrespective of the types of treatment, particularly in control animals (Fig. 4A). Treatment with eCG revealed a significant increase in ovulation rate at 4 weeks of age when given alone $(P<0.0001)$, with anti-BMPRIB $(P<0.001)$ or with antiBMP4 $(P<0.01)$ (Fig. 4A). Treatment of animals with

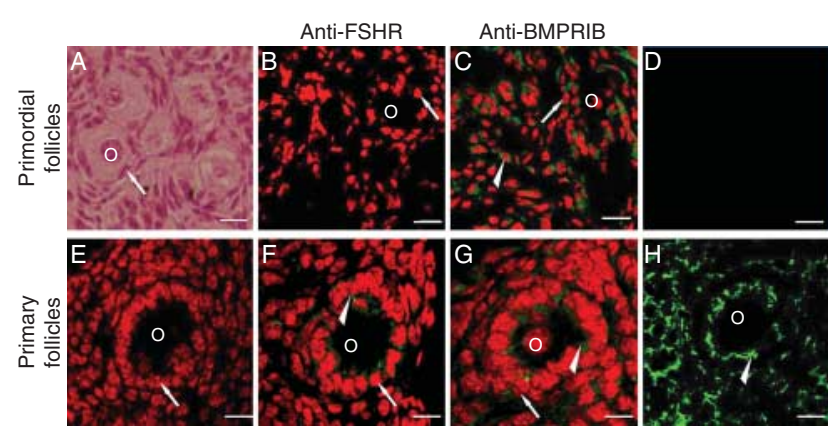

Figure 3 Immunofluorescence localisation of BMPR-IB and FSHR. (A) A histological section stained with $\mathrm{H} \& \mathrm{E}$, showing a group of primordial follicles. (B and C) Groups of primordial follicles showing negative staining for FSHR (B) and positive staining for BMPRIB in follicular cells (C, green). (D) A negative control section using preimmune serum showing no receptor staining. ( $E, F, G$ and $H$ ) Primary follicles reveal positive staining (green) for both FSHR (F) and BMPRIB (G) in granulosa cells. (E) A primary follicle, as shown in (F), observed with a single filter for DAPI, revealing nuclear staining (red) only. $(\mathrm{H})$ A primary follicle, as shown in $(\mathrm{G})$, observed with a single filter for Alexa 488, revealing only positive receptor staining (green) in granulosa and stroma cells. Arrows indicate follicular/granulosa cells stained with DAPI (red). Arrowheads point to positive signals of antibody binding (green). O, oocyte. Bar $=50 \mu \mathrm{m}$.

anti-BMPRIB resulted in a significant increase in ovulation rates at $4(P<0.0001), 10$ and $16(P<0.05)$ weeks when compared with control animals (Fig. 4A, B and $\mathrm{C}$ ). However, although treatment with anti-BMP4 resulted in elevation in ovulation rate across the ages, this was not significant (Fig. 4A).

\section{Discussion}

This study describes how short-term attenuation of the BMP signalling system (1 week) by passive immunisation against BMPRIB and BMP4 can sustain the reserve of primordial follicles while increasing the numbers of developing primary follicles and the rate of ovulation in pre-pubertal mice in vivo. Together with our previous reports (Tanwar et al. 2008, Ruoss et al. 2009), we extend our knowledge regarding the role of the BMP signalling system in the regulation of follicular development. This includes the stimulatory role of these factors in the initial recruitment of primordial follicles to the pool of growing follicles in the rat (Nilsson \& Skinner 2003) and sheep (Ruoss et al. 2009), also their stimulatory role in the ovulation rate and formation of primordial germ cellsand oocytes as previously documented (Moore et al. 2004, Lawson et al. 1999, respectively).

In this study, the resulting changes induced by passive immunisation against the BMP signalling system on both the initial recruitment of follicles and ovulation rate remained for several weeks after treatment. Considering the short half-life of IgG antibody, such an extended effect for several weeks after immunisation was unlikely to have resulted from the direct action of the antibodies. 

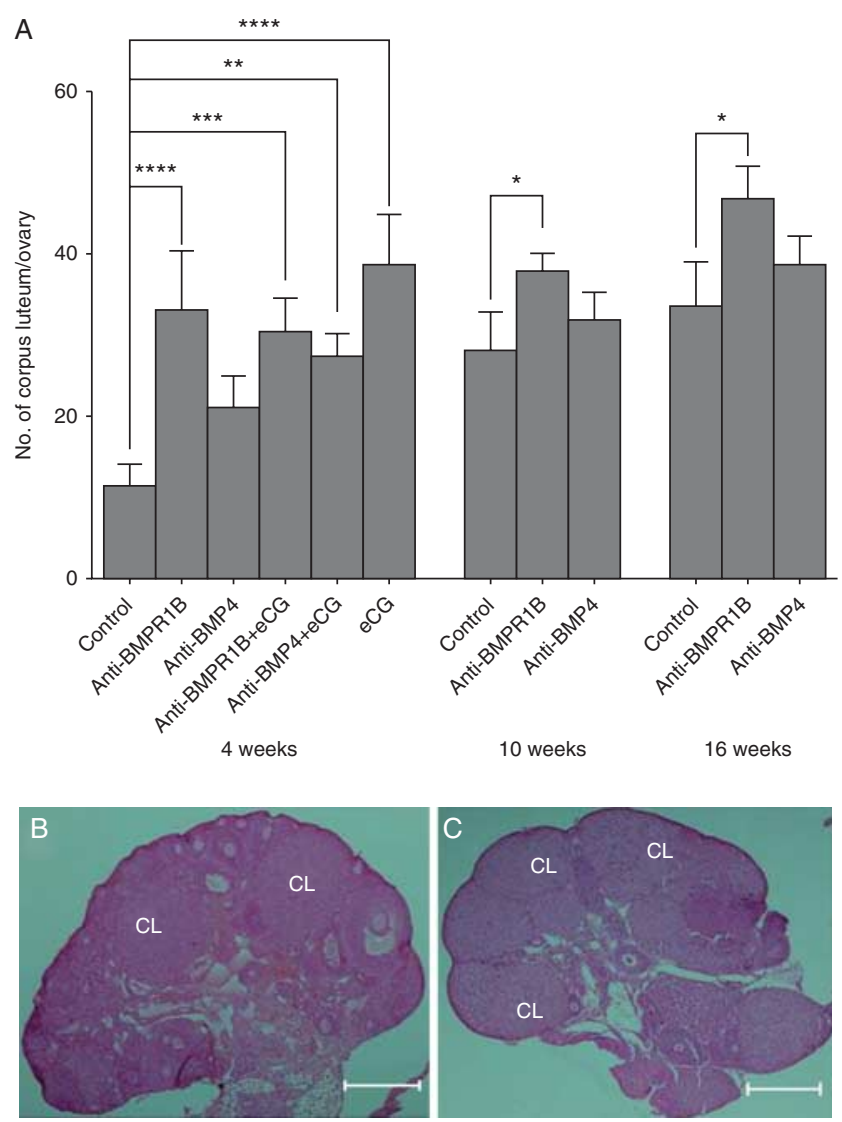

Figure 4 Ovulation rates in animals of different treatment groups. (A) The ovulation rates were estimated in three groups of mice by manually counting the corpora lutea in every 40th serial section (200 $\mu \mathrm{m}$ interval) of individual ovaries. In addition to the increase in ovulation rates with age, the mean \pm s.D. of ovulation rates were significantly higher in treated animals with anti-BMPRIB or eCG with or without antibodies. (B and C) Histological sections showing more corpora lutea in the ovary of treated animals with anti-BMPRIB (C) than in control animals (B). ${ }^{*} P<0.05$; ${ }^{* *} P<0.01$; ${ }^{* * *} P<0.001$;

$* * * * P<0.0001$. CL, corpus luteum. Bar $=100 \mu \mathrm{m}$.

Instead, we believe that the immediate significant increase in primordial follicle population in treated animals compared with controls would have taken several weeks before it was abolished and returned to the normal condition. It is also possible that the noticeably higher magnitude of age-related acceleration of ovulation rate in control animals compared with the treated ones would have over-ridden the significant difference in ovulation rates between the two groups of animals at later ages. These results are similar to those observed in Booroola sheep (Ruoss et al. 2009). However, the receptor mutation-induced effect in sheep is permanent, resulting in an increased longevity of reproduction (Ruoss et al. 2009). In our passive immunised mouse model, the effect is transitory so when the 'effector' is removed the system returns to normal. Nonetheless, the exact intracellular pathway that mediates the effect of passive immunisation on BMP signalling system needs to be clarified.
Interestingly, the effect of immunisation on the preservation of primordial follicles and increasing ovulation rates using anti-BMPRIB was stronger than when using anti-BMP4 antibody. This may be explained by the fact that BMPRIB is a common receptor used by several other BMPs in addition to BMP4 (Nilsson \& Skinner 2003, Shimasaki et al. 2004). Nonetheless, the significant effect induced by BMP4 immunisation ( $>80 \%$ of effect induced by anti-BMPRIB) indicates that BMP4 is likely to be the most effective BMP among other ligands in the process of primordial follicle formation (Lawson et al. 1999) and recruitment (Tanwar et al. 2008) in mice and perhaps less so in later stages of follicular development.

After puberty and irrespective of treatment, the significantly increased degree of depletion of primordial and primary follicles with age is expected, possibly due to increased post-pubertal follicular development and late cyclic recruitment of mature follicles (Broekmans et al. 2007). In support of this, the rate of ovulation was increased with age, therefore indicating that the maturity of animals increased reproductive activity.

Based on our observations, it is interesting to mention that the numbers of primordial follicles in treated and untreated animals continue to decrease with age of mice (these results) and sheep (Ruoss et al. 2009). However, the pattern of such reduction appears species-specific. While in sheep a dramatic decline was observed during the early stages of life (from birth to 1.5 year, Ruoss et al. 2009), it is only observed in older mice at the age of 16 and 28 weeks. In contrast, the numbers of primordial follicles in untreated mice remain unchanged up to the age of 10 weeks. The sustained numbers of primordial follicles over this relatively long period of mouse life may support the previous reports demonstrating the existence of postnatal renewal of primordial follicles in this species (Johnson et al. 2004, Kerr et al. 2006) and more recently in human (White et al. 2012).

More interestingly, in treated animals the numbers of primordial follicles are doubled after immunisation. Such a significant increase is unlikely due to the attenuation of primordial follicle depletion alone. Instead, it appears that in the early-postnatal period of mice, the role of BMPs is not only limited to the stimulation of primordial follicle recruitment but also inhibition of the formation of new primordial germ cells and primordial follicles, a process which reportedly exists in this species (Johnson et al. 2004, Kerr et al. 2006). However, a stimulatory action of BMPs on this process has been reported during mouse foetal development (Lawson et al. 1999). Nonetheless, the numbers of primordial follicles in both treated and untreated animals declined to the level similar to that in older animals of different species and postmenopausal women.

While eCG treatment has remarkable effects on the rate of ovulation as expected, the failure of eCG to induce a detectable effect on initial recruitment of 
primordial follicles supports the notion that this process is gonadotrophin-independent (Lee et al. 2001, Orisaka et al. 2009, Al-Samerria \& Almahbobi 2014) and that there is not a direct action of gonadotrophins on primordial follicles. In support of this, we have found that while the expression of BMPRIB was detectable in follicular cells of mouse primordial follicles, FSHR was absent but later appeared in primary follicles. These data together with a previous report in rat (Moore \& Shimasaki 2005) contradict previous reports (Meredith et al. 1992, Flaws et al. 1997) and therefore suggest the presence of a complex interplay between gonadotrophins and other growth factors such as BMPs where direct and indirect cross-signalling regulates ovarian function (Tanwar \& McFarlane 2011). The reported decrease in primordial follicles after eCG treatment (Tanwar et al. 2008) conflicts with the present result probably due to the manual counting method used in the previous study instead of the automated stereology used in this work. The fact that injection of eCG together with antibody either unexpectedly abolished the effect of immunisation on primordial and primary follicles or reduced the immunisation-induced increases in ovulation rates, requiring further investigation. Meanwhile, we suggest that eCG may act on the larger follicles whereby its action indirectly antagonises the action of the antibodies on the small follicles. Together with previous studies, this study extends our further knowledge regarding the important role of BMPs but not gonadotrophins in the recruitment of initial primordial follicle.

Despite the reduction in the rates of transition of primordial follicles to primary follicles (loss/depletion) in treated animals, the estimated total numbers and ratios of primary follicles derived from primordial follicles in these animals after passive immunisation were significantly increased rather than decreased. This may suggest a reduction in apoptosis, allowing more primary follicles to survive, which requires further investigation. Also, as BMPs exert a proliferative action on granulosa cells, promoting early folliculogenesis and oestrogen production (Guangqin et al. 2013) including the transformation of primary follicles to further developmental stages, immunisation against BMPRIB will slow this action hence resulting the accumulation of more primary follicles.

The novelty of these results may appear inconsistent with a previous study in rat such as that reported by Nilsson \& Skinner (2003). In rat, the addition of more BMPs to cultured ovaries stimulated primordial follicle recruitment, simply monitored by a increased number of primary follicles therefore decrease number of primordial follicles (Nilsson \& Skinner 2003). However, in this study, the attenuation of BMP action by immunisation inhibits primordial follicle recruitment monitored by preservation of these follicles in ovaries when compared with untreated animals. We believe that the significant increase in primordial follicle number in treated animals may also be due to other factors such as stimulation of de novo formation of primordial follicles. On other hand, the increase rather than decrease in the numbers of primary follicles possibly due to inhibition of apoptosis and the transition of primary follicles to developing antral follicles.

In this regard, the previously observed reduced proportion of primary follicles to the total number of the whole follicle population in the ovaries of antiBMP4-treated mice (Tanwar et al. 2008) was probably due to the significant increase in the numbers of primordial follicles after immunisation. As in the case of primordial follicles, the increase in numbers of primary follicles reduced gradually with age after reaching its peak at 10 weeks of age.

In contrast to the case of primordial follicles, eCG treatment alone and in combination with either treatment significantly reduced the numbers and ratios of primary follicles. Evidently, this effect reported in this study cannot be due to a reduced recruitment of primordial to primary follicles, because eCG has no effect on the numbers of primordial follicles and expression of FSHR was not found in primordial follicles. Instead, it is likely that the reduced numbers and ratios of primary follicles resulted from the eCG-induced acceleration of further development of primary follicles and transformation to the stages of secondary and preantral follicles, processes that are promoted by gonadotrophins (Broekmans et al. 2007, Orisaka et al. 2009). Clearly, the more the age of animal the more accelerated the follicle development occurs, and less persistent primary follicles were found as previously reported in older ewes (Ruoss et al. 2009). This effect was more obvious in treated animals probably because of reduced recruitment rates of primordial to primary follicles.

The significant increase in the ovulation rate in mice treated with anti-BMPRIB mimics the well-characterised feature of Booroola sheep (Mulsant et al. 2001, Souza et al. 2002, Ruoss et al. 2009), which exhibit mutation in BMPRIB (Wilson et al. 2001, Campbell et al. 2006, Ruoss et al. 2009). It should be noted that the estimated total numbers of counted corpora lutea represent accumulated ovulation of multiple cycles at a given age. No attempt was made to exclude corpora lutea that were formed and persisted before the treatment because this is a comparative study between treated and untreated animals within each individual age group. The numbers of corpora lutea formed from cycles before the time of treatment were equally present and accounted for in all treated and untreated animals.

The underlying mechanism of BMP action in the regulation of ovulation is not well understood (McNatty et al. 2007). However, it has been reported that BMPs inhibit the gonadotrophin-induced progesterone production by maturing follicles (Xia et al. 2003, Pierre et al. 2004, McNatty et al. 2007), in addition to its inhibitory action on final cell differentiation (Cejalvo et al. 2007), 
in this case granulosa cell luteinisation. In another study, we have found that protein expression of BMPRIB in granulosa cells obtained from IVF patients is significantly downregulated in dominant follicles (Regan et al. 2012). It appears that the downregulation of BMP signalling system is a pre-requisite for the late follicle maturation, granulosa cell differentiation and progesterone formation hence ovulation.

In conclusion, this study demonstrates that the role of the BMP signalling system is likely to be an important regulator of ovarian function, particularly the processes of follicle development, depletion and ovulation. These results, together with our previous studies in mice (Tanwar et al. 2008), sheep (Ruoss et al. 2009) and humans (Regan et al. 2012) and other studies in mice and rats (Lawson et al. 1999, Erickson \& Shimasaki 2003, Nilsson \& Skinner 2003), confirm that this role of BMPs in the regulation of ovarian function is applicable across different species and experimental conditions. We propose that the attenuation of BMP signalling system is an effective approach to increase female fertility reserve while promoting follicle development, ovulation and eventually the overall fertility.

\section{Declaration of interest}

The authors declare that there is no conflict of interest that could be perceived as prejudicing the impartiality of the research reported.

\section{Funding}

This research was funded entirely from internal resources of Curtin and New England Universities. This research did not receive any specific grant from any funding agency in the public, commercial or not-for-profit sector. Co-author I Al-Ali was supported by a postgraduate scholarship from Ministry of Higher Education and Scientific Research and Cultural Relations Directorate, Iraq.

\section{Acknowledgements}

We would like to acknowledge the provision of research facilities and the scientific and technical assistance of the staff of CHIRI Biosciences Research Precinct core facility, Curtin University.

\section{References}

Abir R, Ben-Haroush A, Melamed N, Felz C, Krissi H \& Fisch B 2008 Expression of bone morphogenetic proteins 4 and 7 and their receptors IA, IB, and II in human ovaries from fetuses and adults. Fertility and Sterility 89 1430-1440. (doi:10.1016/j.fertnstert.2007.04.064)

Al-Samerria S \& Almahbobi G 2014 Three-dimensional image analysis to quantify the temporo-spacial expression of cellular receptors. Journal of Medical and Bioengineering 3 179-182.
Braendgaard H \& Gundersen HJ 1986 The impact of recent stereological advances on quantitative studies of the nervous system. Journal of Neuroscience Methods 18 39-78. (doi:10.1016/0165-0270(86)90112-3)

Broekmans FJ, Knauff EA, te Velde ER, Macklon NS \& Fauser BC 2007 Female reproductive ageing: current knowledge and future trends. Trends in Endocrinology and Metabolism 18 58-65. (doi:10.1016/j.tem.2007. 01.004)

Campbell BK, Souza CJ, Skinner AJ, Webb R \& Baird DT 2006 Enhanced response of granulosa and theca cells from sheep carriers of the FecB mutation in vitro to gonadotropins and bone morphogenic protein-2, -4 , and -6. Endocrinology 147 1608-1620. (doi:10.1210/en.2005-0604)

Cejalvo T, Sacedon R, Hernandez-Lopez C, Diez B, Gutierrez-Frias C, Valencia J, Zapata AG, Varas A \& Vicente A 2007 Bone morphogenetic protein-2/4 signalling pathway components are expressed in the human thymus and inhibit early T-cell development. Immunology 121 94-104. (doi:10.1111/j.1365-2567.2007.02541.x)

Chang H, Brown CW \& Matzuk MM 2002 Genetic analysis of the mammalian transforming growth factor- $\beta$ superfamily. Endocrine Reviews 23 787-823. (doi:10.1210/er.2002-0003)

Cheifetz S, Weatherbee JA, Tsang ML, Anderson JK, Mole JE, Lucas R \& Massague J 1987 The transforming growth factor- $\beta$ system, a complex pattern of cross-reactive ligands and receptors. Cell 48 409-415. (doi:10. 1016/0092-8674(87)90192-9)

Depalo R, Nappi L, Loverro G, Bettocchi S, Caruso ML, Valentini AM \& Selvaggi L 2003 Evidence of apoptosis in human primordial and primary follicles. Human Reproduction 18 2678-2682. (doi:10.1093/humrep/ $\operatorname{deg} 507)$

Derynck R \& Zhang YE 2003 Smad-dependent and Smad-independent pathways in TGF- $\beta$ family signalling. Nature 425 577-584. (doi:10.1038/ nature02006)

Dierich A, Sairam MR, Monaco L, Fimia GM, Gansmuller A, LeMeur M \& Sassone-Corsi P 1998 Impairing follicle-stimulating hormone (FSH) signaling in vivo: targeted disruption of the $\mathrm{FSH}$ receptor leads to aberrant gametogenesis and hormonal imbalance. PNAS 95 13612-13617. (doi:10.1073/pnas.95.23.13612)

Erickson GF \& Shimasaki S 2003 The spatiotemporal expression pattern of the bone morphogenetic protein family in rat ovary cell types during the estrous cycle. Reproductive Biology and Endocrinology 1 9. (doi:10. 1186/1477-7827-1-9)

Fauser BC \& Van Heusden AM 1997 Manipulation of human ovarian function: physiological concepts and clinical consequences. Endocrine Reviews 18 71-106.

Flaws JA, Abbud R, Mann RJ, Nilson JH \& Hirshfield AN 1997 Chronically elevated luteinizing hormone depletes primordial follicles in the mouse ovary. Biology of Reproduction 57 1233-1237. (doi:10.1095/biolreprod57.5.1233)

Guangqin Z, Yihong C, Jiangang W, Yuxuan S \& Binyun C 2013 Bone morphogenetic proteins (BMP) 2, 4, 6 and 7 affect ovarian follicular development through regulation of follicle-stimulating hormone receptor (FSHR) and luteinizing hormone receptor (LHR) expression in goat granulosa cells. Journal of Cell Biology and Genetics 3 14-21. (doi:10. 5897/JCBG12.004)

Gundersen HJ, Bagger P, Bendtsen TF, Evans SM, Korbo L, Marcussen N, Moller A, Nielsen K, Nyengaard JR, Pakkenberg B et al. 1988 The new stereological tools: disector, fractionator, nucleator and point sampled intercepts and their use in pathological research and diagnosis. APMIS: Acta Pathologica, Microbiologica, et Immunologica Scandinavica 96 857-881. (doi:10.1111/j.1699-0463.1988.tb00954.x)

Hall PF \& Almahbobi G 1997 Roles of microfilaments and intermediate filaments in adrenal steroidogenesis. Microscopy Research and Technique 36 463-479. (doi:10.1002/(SICl)1097-0029(19970315)36:6<463 ::AID-JEMT4 > 3.0.CO;2-J)

Johnson J, Canning J, Kaneko T, Pru JK \& Tilly JL 2004 Germline stem cells and follicular renewal in the postnatal mammalian ovary. Nature $\mathbf{4 2 8}$ 145-150. (doi:10.1038/nature02316)

Kerr JB, Duckett R, Myers M, Britt KL, Mladenovska T \& Findlay JK 2006 Quantification of healthy follicles in the neonatal and adult mouse ovary: evidence for maintenance of primordial follicle supply. Reproduction 132 95-109. (doi:10.1530/rep.1.01128)

Knight PG \& Glister C 2003 Local roles of TGF- $\beta$ superfamily members in the control of ovarian follicle development. Animal Reproduction Science 78 165-183. (doi:10.1016/S0378-4320(03)00089-7) 
Lawson KA, Dunn NR, Roelen BA, Zeinstra LM, Davis AM, Wright CV, Korving JP \& Hogan BL 1999 Bmp4 is required for the generation of primordial germ cells in the mouse embryo. Genes and Development 13 424-436. (doi:10.1101/gad.13.4.424)

Lee WS, Otsuka F, Moore RK \& Shimasaki S 2001 Effect of bone morphogenetic protein-7 on folliculogenesis and ovulation in the rat. Biology of Reproduction 65 994-999. (doi:10.1095/biolreprod65.4.994)

Massague J 1998 TGF- $\beta$ signal transduction. Annual Review of Biochemistry 67 753-791. (doi:10.1146/annurev.biochem.67.1.753)

McGee EA \& Hsueh AJ 2000 Initial and cyclic recruitment of ovarian follicles. Endocrine Reviews 21 200-214.

McKinney MM \& Parkinson A 1987 A simple, non-chromatographic procedure to purify immunoglobulins from serum and ascites fluid. Journal of Immunological Methods 96 271-278. (doi:10.1016/00221759(87)90324-3)

McNatty KP, Hudson NL, Whiting L, Reader KL, Lun S, Western A, Heath DA, Smith P, Moore LG \& Juengel JL 2007 The effects of immunizing sheep with different BMP15 or GDF9 peptide sequences on ovarian follicular activity and ovulation rate. Biology of Reproduction 76 552-560. (doi:10.1095/biolreprod.106.054361)

Meredith S, Dudenhoeffer G, Butcher RL, Lerner SP \& Walls T 1992 Unilateral ovariectomy increases loss of primordial follicles and is associated with increased metestrous concentration of follicle-stimulating hormone in old rats. Biology of Reproduction 47 162-168. (doi:10. 1095/biolreprod47.2.162)

Moore RK \& Shimasaki S 2005 Molecular biology and physiological role of the oocyte factor, BMP-15. Molecular and Cellular Endocrinology 234 67-73. (doi:10.1016/j.mce.2004.10.012)

Moore RK, Erickson GF \& Shimasaki S 2004 Are BMP-15 and GDF-9 primary determinants of ovulation quota in mammals? Trends in Endocrinology and Metabolism 15 356-361. (doi:10.1016/j.tem.2004. 08.008)

Mulsant P, Lecerf F, Fabre S, Schibler L, Monget P, Lanneluc I, Pisselet C, Riquet J, Monniaux D, Callebaut I et al. 2001 Mutation in bone morphogenetic protein receptor-IB is associated with increased ovulation rate in Booroola Merino ewes. PNAS 98 5104-5109. (doi:10. 1073/pnas.091577598)

Myers M, Britt KL, Wreford NG, Ebling FJ \& Kerr JB 2004 Methods for quantifying follicular numbers within the mouse ovary. Reproduction 127 569-580. (doi:10.1530/rep.1.00095)

Nilsson EE \& Skinner MK 2003 Bone morphogenetic protein-4 acts as an ovarian follicle survival factor and promotes primordial follicle development. Biology of Reproduction 69 1265-1272. (doi:10.1095/ biolreprod.103.018671)

Orisaka M, Tajima K, Tsang BK \& Kotsuji F 2009 Oocyte-granulosa-theca cell interactions during preantral follicular development. Journal of Ovarian Research 2 9. (doi:10.1186/1757-2215-2-9)

Pierre A, Pisselet C, Dupont J, Mandon-Pepin B, Monniaux D, Monget P \& Fabre S 2004 Molecular basis of bone morphogenetic protein-4 inhibitory action on progesterone secretion by ovine granulosa cells. Journal of Molecular Endocrinology 33 805-817. (doi:10.1677/jme.1. 01545)

Regan S, Stanger J, Yovich JL \& Almahbobi G 2012 Growth hormone increase gonadotropin receptor in poor-prognosis patients. Human Reproduction 27525.
Ruoss C, Tadros A, O'Shea T, McFarlane J \& Almahbobi G 2009 Ovarian follicle development in Booroola sheep exhibiting impaired bone morphogenetic protein signalling pathway. Reproduction 138 689-696. (doi:10.1530/REP-09-0190)

Sandrock M, Schulz A, Merkwitz C, Schoneberg T, Spanel-Borowski K \& Ricken A 2009 Reduction in corpora lutea number in obese melanocortin-4-receptor-deficient mice. Reproductive Biology and Endocrinology 7 24. (doi:10.1186/1477-7827-7-24)

Shimasaki S, Zachow RJ, Li D, Kim H, lemura S, Ueno N, Sampath K, Chang RJ \& Erickson GF 1999 A functional bone morphogenetic protein system in the ovary. PNAS 96 7282-7287. (doi:10.1073/pnas.96.13. 7282)

Shimasaki S, Moore RK, Otsuka F \& Erickson GF 2004 The bone morphogenetic protein system in mammalian reproduction. Endocrine Reviews 25 72-101. (doi:10.1210/er.2003-0007)

Siegel ET, Kim HG, Nishimoto HK \& Layman LC 2013 The molecular basis of impaired follicle-stimulating hormone action: evidence from human mutations and mouse models. Reproductive Sciences 20 211-233. (doi:10.1177/1933719112461184)

Souza CJ, Campbell BK, McNeilly AS \& Baird DT 2002 Effect of bone morphogenetic protein 2 (BMP2) on oestradiol and inhibin A production by sheep granulosa cells, and localization of BMP receptors in the ovary by immunohistochemistry. Reproduction 123 363-369. (doi:10.1530/ rep.0.1230363)

Tanwar PS \& McFarlane JR 2011 Dynamic expression of bone morphogenetic protein 4 in reproductive organs of female mice. Reproduction 142 573-579. (doi:10.1530/REP-10-0299)

Tanwar PS, O'Shea T \& McFarlane JR 2008 In vivo evidence of role of bone morphogenetic protein-4 in the mouse ovary. Animal Reproduction Science 106 232-240. (doi:10.1016/j.anireprosci.2007.04.015)

Thomas FH \& Vanderhyden BC 2006 Oocyte-granulosa cell interactions during mouse follicular development: regulation of kit ligand expression and its role in oocyte growth. Reproductive Biology and Endocrinology 4 19. (doi:10.1186/1477-7827-4-19)

White YAR, Woods DC, Takai Y, Ishihara O, Seki H \& Tilly JL 2012 Oocyte formation by mitotically active germ cells purified from ovaries of reproductive-age women. Nature Medicine 18 413-421. (doi:10.1038/ nm.2669)

Wilson T, Wu XY, Juengel JL, Ross IK, Lumsden JM, Lord EA, Dodds KG, Walling GA, McEwan JC, O'Connell AR et al. 2001 Highly prolific Booroola sheep have a mutation in the intracellular kinase domain of bone morphogenetic protein IB receptor (ALK-6) that is expressed in both oocytes and granulosa cells. Biology of Reproduction 64 1225-1235. (doi:10.1095/biolreprod64.4.1225)

Xia Y, O'Shea T, Murison R \& McFarlane JR 2003 Concentrations of progesterone, follistatin, and follicle-stimulating hormone in peripheral plasma across the estrous cycle and pregnancy in merino ewes that are homozygous or noncarriers of the Booroola gene. Biology of Reproduction 69 1079-1084. (doi:10.1095/biolreprod.102.005512)

Received 28 August 2014

First decision 30 September 2014

Revised manuscript received 3 February 2015

Accepted 9 February 2015 